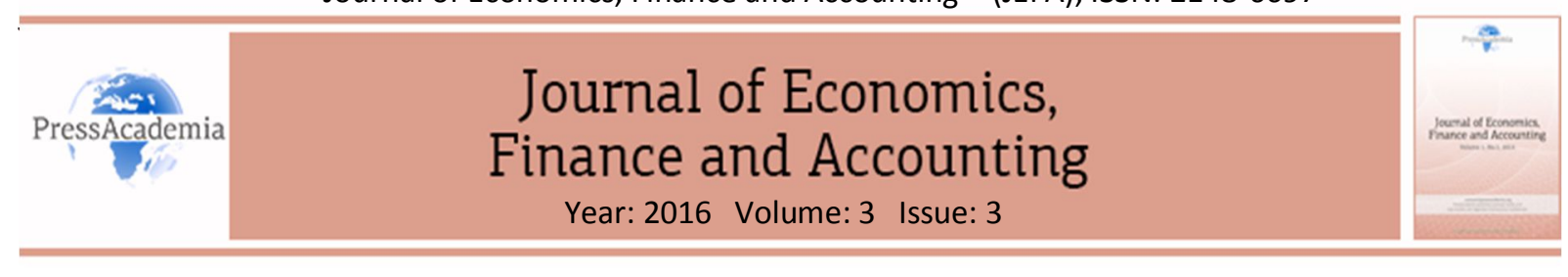

\title{
ANALYSIS OF THE RELATIONSHIP BETWEEN INFLATION AND ECONOMIC GROWTH IN TURKEY
}

DOI: 10.17261/Pressacademia.2016321986

\section{Aylin Idikut Ozpence}

Pamukkale Üniversitesi, aidikut@pau.edu.tr

\begin{abstract}
The link between inflation (CPI) and economic growth (Real GDP) is the one of the main issues of macroeconomics. Many theoretical and empirical studies has discussed this topic. Therefore, this relationship in the economics literature investigate with different countries, period and empirical studies. There is no consensus on this relationship in empirical evidences. The main purpose of this study is to determine whether there is a causal relationship between inflation and economic growth in Turkey's economy between the period 2003:12015:4. To analyze this relationship we used Vector Autoregressive Model (VAR) and Granger causality test. Our findings indicate that there is one-directional causal link from economic growth to inflation. With this aspect of study is distinguished from conducted other studies for Turkey. Especially, within this period 2002 Emergency Action Plan which was put into practice after 2001 economic crisis and the contraction in the world economy caused a domestic-demand-based economic growth in Turkey. Hence, our findings are in accordance with these economic circumstances.
\end{abstract}

Keywords: Inflation, Economic Growth, Turkey, Vector Autoregressive Model (VAR), Granger Causality JEL Classification: P44, 047, C32

\section{TÜRKIYE'DE ENFLASYON VE EKONOMIK BÜYÜME ILIŞKISININ ANALIZi}

\section{ÖZET}

Enflasyon ile ekonomik büyüme arasındaki ilişki makroekonominin temel çalışma alanlarından birini oluşturmaktadır. Bu iki değişkenin birbirleri üzerinde etkisi en çok tartışılan konular arasında yer almaktadır. Bu nedenle bu ilişki iktisat yazınında farklı ülkeler, dönemler ve ampirik çalışmalarla araştırılmaktadır. Söz konusu ilişkiyi test eden ampirik çalışmalardaki sonuçlarda ise bir fikir birliğinden bahsetmek mümkün görünmemektedir. Bu çalışmanın temel amacı Türkiye ekonomisinde 2003:1-2015:4 yılları arasında enflasyon (TÜFE) ve ekonomik büyüme (reel GSYiH) arasında bir ilişkinin var olup olmadığını belirlemektir. Bu amaçla çalışmada Vektör Otoregresif Model (VAR) ve Granger nedensellik testi uygulanmıştır. Ulaşılan sonuçlara göre enflasyon ile ekonomik büyüme arasındaki nedensellik ilişkisinde ekonomik büyümeden enflasyona doğru istatistiksel anlamlı ve tek yönlü nedensellik tespit edilmiştir. Bu yönüyle çalışma, Türkiye için yapılmış diğer çalışmalardan farklılıklar ortaya koymaktadır. Özellikle 2001 yılında yaşanan ulusal krizin ardından bir dizi yapısal reform sunan 2002 Acil Eylem Planı, dünya ekonomisinde yaşanılan daralmalar, Türkiye'de iç talebe dayalı ekonomik büyümenin enflasyonu etkilemesi, sonuçlarla örtüşmektedir.

Anahtar Kelimeler : Enflasyon, Ekonomik Büyüme, Türkiye, Vektör Otoregresif Model (VAR), Granger Nedensellik

JEL Sınıflandırması : P44, 047, C32

\section{GiRiş}

Ne zaman ki ekonomik aktörlerin satın alma gücü değişti işte o zaman enflasyon ilgi odağı haline geldi. İktisadi düşünceler kapsamında da teoriler ekonomileri ekonomiler de teorileri şekillendirdi. Ekonomik gelişmeler yaşandıkça yeni kavramlar ve yeni olgular ortaya çıktı. Enflasyonda bu kapsamda önceleri zararsız bir olgu 
olarak düşünülürken ve tabi ki buna yönelik teorik açılımlar yapılırken -Klasik iktisadi Düşünce- derinleşen sonuçlarına çözüm bulunamayınca hatta göz ardı edilince -Keynesyen Yaklaşım- yeni teoriler ileri sürüldü Neoklasik iktisadi Düşünce-.teori ile uygulama arasında yaşanan bazen örtüşme bazen de çelişme süreçleri üzerinde özel inceleme gerektiren makroekonomik göstergelerin birbirleriyle etkileşimleri akademik çalışmaların konusunu oluşturdu. Bu çerçeveden bakıldığında çalışmanın ana konusunu oluşturan enflasyon ve ekonomik büyüme ilişkisi Türkiye özelinde ele alınmaktadır.

İkinci Dünya Savaşı'ndan sonra enflasyon ve ekonomik büyüme ilişkisi akademi camiasında merak edilen konular arasına girmiştir. Savaştan önce enflasyonun ekonomik büyüme üzerindeki etkilerinin pozitif nitelikte olduğuna dair çalışmalar çoğunluktayken savaştan sonra refah devleti uygulamaları ile birlikte ülkeler en güzel dönemlerini yaşamıştır. Keynesyen politikaların hakim olduğu bu dönemde Philips Eğrisi ile yüksek enflasyonun düşük oranlı bir işsizlik ile ekonomik büyüme üzerinde pozitif etkiler yarattığını ileri sürülmesi teorik açıdan da bir kanıt niteliği taşımaktaydı. 1950'li yıllarda ise yapısalcılar-pozitif etki- ve monetaristler-negatif etki- arasında uzun süren bir tartışma konusu olmuştur. 1970'li yıllara gelindiğinde ise petrol krizleri ile birlikte önü kesilemeyen enflasyon olgusu -hiperenflasyon- neticesinde enflasyonun büyümeyi negatif yönde etkilediğine dair araştırmalar artarak devam eder hale gelmiştir. Akademik çalışmalar arasında enflasyonla ekonomik büyüme arasındaki ilişkinin nötr olduğuna dair kanıtlar da mevcuttur. Bunun yanında eşik değer kabul edilen yöntemlerle de söz konusu ilişki irdelenmektedir. Söz konusu ilişkiye geniş çapta bakıldığında özellikle ampirik çalışmalarda bir fikir birliğinden bahsetmek mümkün değildir. Kanaatimizce bu durum ekonomilerin dinamik yapılarından kaynaklanmaktadır.

Enflasyonla ekonomik büyüme arasındaki ilişkiye gelişmekte olan ülkeler açııından bakıldığında ise negatif ilişkinin yüksek seviyelerde seyreden enflasyonun ekonomik ortamda yarattığı belirsizlikler şeklinde ortaya çıktığını görmekteyiz. Bu durum fiyatlar ve uygulanacak ya da uygulanan politikalar arasında tutarsızlığa sebep olmaktadır.

Çalışmada ilk olarak enflasyon ile ekonomik büyüme arasındaki ilişkiyi tartışan farklı ekonomik teoriler ve literatür taramasına yer verilmiştir. Türkiye'de enflasyon ve ekonomik büyüme etkileşimi sorunsalına cevap arayan çalışmaya, veri ve yöntemlerin tanıtılması ile devam edilmiştir. Bulgular ve tartışma kısmını ise sonuç ve değerlendirme bölümü izlemiştir.

\section{TEORIK ÇERÇEVE VE LITERATÜR TARAMASI}

Baumol'a göre ekonomik büyüme ve fiyat düzeyi arasında iki yönlü ilişki vardır. Yani ekonomik büyüme fiyat hareketlerini fiyat hareketleri de ekonomik büyümeyi etkilemektedir. Fiyat düzeyleri üzerinde ekonomik büyümenin etkisine bakıldığında; ekonomik büyüme fiyatlar üzerinde yukarı yönlü bir baskı oluşturmaktadır. İstihdam seviyesi yüksekken doğal kaynakların sahipleri fiyatlarını arttıracaktır. Sendikalar da daha yüksek ücret talep edeceklerdir. Artan üretim faktörlerinin fiyatları nihai ürün fiyatlarını da arttıracaktır. İ̧ adamları da bu talepleri karşı koymayacaktır. Çünkü onların deneyimleri genişleme döneminde satışlarında ciddi bir etki yaratmadan fiyatlarını arttırabileceklerini göstermektedir. Artan maliyetler daha yüksek bir gelire dolayısıyla da daha yüksek bir satın alma gücüne dönüşecektir. Ekonomik büyüme üzerindeki fiyatların etkisi; belli bir noktaya kadar yavaş yavaş yükselen fiyatlar ekonomik büyüme üzerinde uyarıcı bir etkiye sahiptir. Ekonomide iyimser bir atmosfer yaratarak ekonomik büyümeyi arttırır (Baumol, 1958).

iktisat yazınında ekonomiler içerisinde ekonomik büyümenin nasıl sağlanacağı konusunda bir fikir birliği sağlanamamışıı. Klasik-neoklasik iktisadi düşünce ekonomik büyümeyi arz yönlü açıklarken Keynes-Post Keynesyen Yaklaşım ise talep yönlü açıklamaktadır. Neoklasik iktisatta sermaye birikimi, işgücü ve teknoloji temel belirleyiciyken tasarruflar yatırımları belirlemektedir. Bunlara ilaveten ekonomik büyümenin sağlanması için devlete düşen görevler açısından da farklı fikirler ileri sürmüştür. Neoklasiklerde Solow, sermaye birikimini dikkate alarak, devletin uygulayacağı politikaların büyüme üzerinde çok fazla bir etkide bulunamayacağını vurgulamıştır (Solow, 1956). Ancak yine neoklasik iktisadi görüş kapsamında değerlendirebileceğimiz içsel büyüme teorileri kapsamında devlet, büyümenin sağlanması noktasında aktif bir rol üstlenmektedir. Beşeri sermayenin, eğitimin, Ar-Ge'nin, teknolojinin ve bilgi birikiminin geliştirilmesi ile ekonomiler büyüme hızlarını arttırabilmektedir. Devletin bu konularda yapacağı aktif politikalarla arzu edilen büyüme oranının yakalanması sağlanacaktır (Romer, 1986; Lucas, 1988; Barro ve Sala-i-Martin, 1992). İçsel büyüme modelleri enflasyonu vergi 
gibi kabul ettikleri için -sermayenin artan getirisi koşulu altında- enflasyonun ekonomik büyümeyi negatif yönde etkileyeceğini ileri sürmektedir.

Keynesyen ve Postkeynesyen Yaklaşımın ekonomik büyüme teorilerinde öne çıkan modeller Harrod-Domar ve Kaldor'un ileri sürdüğü modellerdir. Harrod (1939) ve Domar (1946) yaptıkları iki farklı çalışmada hemen hemen aynı sonuçları elde etmişler ve bu sonuçlar iktisat yazınına Harrod-Domar büyüme modeli olarak geçmiştir. Harrod (1939), hızlandıran prensibi ve çarpan teorisini oluşturan temel denge olarak gerekli ekonomik büyüme oranını; bireylerin ve tüzel kişilerin tasarruf etmeyi tercih ettikleri gelirlerinin bir bölümünün çıktının bir birim artış üretimi için gerekli olan sermaye mallarının değerine oranı olarak formüle etmektedir. Domar (1946), sermaye birikimi, yatırım ve istihdam arasındaki ilişkiyi inceleyen çalışmasında yatırımların firmalar ve tüm ekonomi için farklı anlamlara geldiğini belirtmektedir. Her iki kesim de yatırımları verimli alanlarda kullanırlarsa ekonomik büyüme gerçekleşecektir.

Kaldor’a göre ekonomik büyüme efektif talebe göre değil çıktının genel düzeyine göre belirlenen mevcut kaynaklara göre sağlanmaktadır. Teknolojik ilerleme verimliliği arttırmaktadır yani neoklasiklerin ileri sürdüğü gibi dışsal değildir. Kaldor'un modeli de diğer makroekonomik modeller gibi gelirin, sermayenin, karların, ücretlerin, yatırımların ve tasarrufların basit toplamlarından oluşmaktadır. Ekonomik büyüme sürecinde itici güç sermaye yatırımlarıdır. Para politikası pasiftir ve neoklasiklerin belirttiği teknolojik seçimler üzerinde sermayenin ve ücretlerin kar oranı etkili değildir (Kaldor, 1957).

Enflasyonun ekonomik büyüme üzerindeki etkisi makroekonomi içerisinde çalışmanın kapsamını oluşturan maliye politikasında incelenen temel konulardan biridir. Maliye politikasının ekonomik istikrarı sağlama amaçlarından biri olan fiyat istikrarını sağlama birçok ampirik çalışmaya konu olmuştur. Söz konusu bu çalışmalar incelendiğinde enflasyonun ekonomik büyüme üzerindeki etkisi ya nötr ya negatif ya da pozitif niteliktedir. Bunun yanında enflasyon oranına eşik değer verilerek enflasyon ve ekonomik büyüme ilişkisi test edilmektedir.

Sidrauski, Neoklasik büyüme modelinde olduğu gibi paranın nötr olduğunu hatta güçlü yansız olduğunu belirtmiştir. Sidrauski parasal büyüme modeline göre parasal genişleme oranlarındaki bir değişimin kısa ve uzun dönemde büyüme üzerindeki etkisini incelediği çalışmasında kısa dönemde parasal genişlemedeki bir değişimin sermaye birikimi oranında bir azalışa neden olurken uzun dönemde sermaye stokunda bir etkide bulunmamaktadır (Sidrauski, 1967a). Tasarruflar gelirin sabit bir fonksiyonu ve fiyatlar esnekken para stokundaki değişiklik nötrdür ancak parasal genişleme ya da para arzındaki değişiklikler süper nötrdür. Para stoku iki kat arttırılırsa fiyatlar da iki katına çıkar ancak ekonominin reel değişkenleri kısa ve uzun dönemde de değişmez (Sidrauski, 1967b).

Neoklasik ekonomik büyüme modellerinin çoğu parasal olmayan parayı bir servet unsuru olarak kabul etmeyen şekildedir yani bireylerin portföy tercihlerini dikkate almamaktadır. Bu noktadan hareketle Mundell-Tobin Etkisi olarak iktisat yazınına geçen ve enflasyonla ekonomik büyüme arasında pozitif ilişkinin olduğunu vurgulayan yaklaşıma göre, yüksek bir enflasyon oranı bireylerin parayı tasarruf etme ve elde tutma (değer saklama) maliyetlerini arttırmaktadır. Böylelikle bireyler yüksek enflasyon nedeniyle zorunlu tasarruf mekanizmasının harekete geçmesiyle birlikte sermaye birikimine karar verirler. Bu durum faiz oranlarını düşürerek ekonomik büyümeyi arttıracaktır. Klasik iktisadi düşünceye göre faiz oranları ve sermaye yoğunluğu, verimlilik ve tasarruf yani tasarruf eğilimi ve teknoloji etkileşimi tarafından belirlenmektedir. Kısa dönem için bu durumu kabul eden Tobin, Keynes'in de kısa dönemde faiz oranları ve sermaye birikimi üzerinde etkili olduğunu belirttiği parasal faktörlerin ve portföy kararlarının uzun dönemde de geçerli olduğunu belirtmiştir (Tobin, 1965). Mundell (1965), enflasyon ile ekonomik büyüme arasındaki ilişkiyi parasal faktörlerle açıklamıştır. Enflasyon oranı, parasal genişleme oranından ekonomik büyüme oranının çıkarılması sonucu belirlenmektedir. Yani enflasyon ile ekonomik büyüme arasında pozitif bir ilişki bulunmaktadır. Toplam talep-toplam arz sisteminde de enflasyon ve ekonomik büyüme arasındaki pozitif ilişkinin olduğu ispatsız olarak kabul edilmektedir (Gokal ve Hanif, 2004). Enflasyon ile ekonomik büyüme arasında pozitif ilişki olduğunu belirten bir diğer çalışmada Mallik ve Chowdhury'e (2001) aittir. Bangladeş, Hindistan, Pakistan ve Sri Lanka ülkelerinden oluşan örneklemeye göre ekonomik büyüme oranlarındaki değişimlere enflasyonun duyarlılı̆̆ı, enflasyon oranlarındaki değişimlere ekonomik büyümenin duyarlılığından daha fazladır (Mallik ve Chowdhury, 2001). 1970'lerde stagflasyon olgusunun yaşanması söz konusu pozitif ilişkinin sorgulanmasına neden olmuştur. 
Enflasyonla ekonomik büyüme arasında negatif ilişki olduğunu vurgulayan neoklasik iktisadın görüşlerini destekler nitelikte Barro (1995) doğurganlık oranı, eğitim, yatırımlar vb. gibi değişkenleri de dikkate alarak yaptığı çalışmasında ekonomik büyüme üzerindeki enflasyonun etkisini regresyon denge modeli kurarak analiz etmiş ve enflasyon ile ekonomik büyüme arasındaki ilişkiyi negatif bulmuştur. Uzun dönemli yüksek bir enflasyon oranı ekonomik büyüme ve yatırımlar da azalışa neden olmaktadır. Enflasyon oranında yaşanabilecek yüzde $10^{\prime}$ luk bir artış GSYIH'de yaklaşık yüzde 0.2 oranında bir azalışa yol açmaktadır. Barro, bu çalışmasında neoklasik büyüme modelini genişletilmiş bir çerçeveye dayandırmaktadır. Tun Wai (1959), 1938-1950 ${ }^{1}$ yılları arasında Türkiye'nin içinde bulunduğu 31 kalkınmakta olan ülkeyi ele aldığı çalışmasında Meksika haricindeki ülkelerin daha düşük enflasyon oranına sahip olduğu dönemlerde daha yüksek oranda kalkınma sağladıklarını ortaya çıkarmıştır.

Ekonomik büyüme üzerinde enflasyonun negatif etkisini 1961-1997 yılları arasında OECD ve APEC ülkelerinin verilerinden oluşan ampirik bir modelle açıklayan Gillman vd. (2002), teoride olduğu gibi OECD ülkeleri için enflasyon oranları yüzde 0-10 arası olan ülkelerde negatif bulmuştur. APEC ülkeleri için ise bu etki daha zayıftır (Gillman vd., 2002). Geçiş ekonomilerinde 1990-2003 yılları arasında büyüme üzerindeki enflasyonun etkisini Panel data veri analizi ile ölçen Gillman ve Harris (2010), ilişkiyi yine negatif bulmuştur.

Enflasyon ekonomik verimliliğe engel olduğu ölçüde ekonomi üzerinde negatif dışsallıklara da neden olmaktadır. Özellikle de enflasyon oranı uzun dönem boyunca yüksek oranda seyrederse ekonomide gelecekle ilgili belirsizliği ve bütçe açığını arttırmaktadır (Borrero, 2001; Gokal ve Hanif: 2004). Enflasyon; tüketim, tasarruf ve yatırım kararları üzerinde belirsizliği de arttırmaktadır.

Ekonomik büyüme üzerindeki enflasyonun doğrusal olmayan ve eşik değer etkisini araştıran çalışmalarda bulunmaktadır. Enflasyon oranı eşik değeri aşmadığı takdirde ekonomik büyümeyi pozitif eğer aşarsa negatif yönlü etkilemektedir. Doğrusal olmayan ilişkiyi ilk defa Fischer (1993) ileri sürmüş ve 1960-1989 yılları arasında 101 ülkenin verilerinden oluşan yatay kesit ve panel veri analizi sonucunda, enflasyon ve büyüme arasında negatif bir ilişki bulmuştur. Fischer'e göre makroekonomik politikaların temel göstergeleri enflasyon ve bütçe fazlası ya da açığıdır. Aynı zamanda ekonomik büyümeye vesile olan temel göstergelerden birincisi enflasyon ikincisi de bütçe fazlası ya da açığıdır. Hatta enflasyon oranı hükümetlerin ekonomiyi yönetme kabiliyetinin bir göstergesi olarak kabul edilmektedir.

Sarel (1996) 1970-1990 dönemleri arasında 87 ülkeyi incelediği çalışmasında panel data sonuçlarına göre yüzde 8 enflasyon eşik değerini aşan ülkelerde enflasyonla ekonomik büyüme arasında negatif bir ilişki olduğunu belirtmektedir. Khan ve Senhadji (2001), gelişmiş ve gelişmekte olan ülkelerden oluşan 140 ülkeyi kapsayan ve 1960-98 yılları arasındaki verilerden oluşan doğrusal olmayan en küçük kareler yöntemine göre gelişmekte olan ülkelerde yüzde 1-3 ve gelişmiş ülkelerde yüzde 11-12 oranında bir eşik değer belirleyerek enflasyon ve ekonomik büyüme arasındaki ilişkiyi negatif bulmuştur. Diğer bir çalışma da Ghosh ve Phillips'e (1998) aittir. 145 ülkenin verilerinden oluşan ve 1960-1996 yılları arasını kapsayan çalışmada enflasyon oranının eşik değeri yüzde 2.5 oranında tahmin edilmiştir (Ghos ve Phillips, 1998). Bruno ve Easterly (1998), enflasyon ve ekonomik büyüme arasında uzun dönemde yatay kesit korelasyon olmadığını ancak enflasyon oranında yüzde 40’ık bir eşik değer aşılırsa ilişkinin negatif olacağını belirtmiştir. Mubarik (2005), Pakistan için 1973-2000 yılları arasını kapsayan çalışmasında enflasyonun eşik değer olan yüzde 9 oranını aşması durumunda ekonomik büyümenin kırmızı alarm verdiğini ve enflasyondan ekonomik büyümeye doğru negatif bir nedenselliğin olduğunu vurgulamaktadır. Ahmed ve Mortaza (2005) Bangladeş kapsamında yaptığı çalışmada uzun dönemde enflasyondan ekonomik büyümeye doğru negatif bir etkinin olduğunu belirtmektedir.

Enflasyon ile ekonomik büyüme arasında negatif ilişki olduğunu ileri süren ülke/ler bazında yapılan çalışmalar da bulunmaktadır. Faria ve Carneiro (2001) Brezilya için kısa dönemde negatif olan ilişkinin uzun dönemde pozitif olduğunu belirtmektedir. Sri Lanka ülkesi için uzun dönemde negatif olan ilişki Çin ve Hindistan için söz konusu değildir. Kısa dönemde ise sadece Çin için ilişki negatiftir (Jayathileke ve Rathnayake, 2013).

Bozkurt (2014), Türkiye için yaptığı çalışmasında 1999.2 - 2012.2 yılları çeyreklik dönemler arasında koentegrasyon uygulama yöntemini kullanarak para, enflasyon ve büyüme arasındaki ilişkiyi incelemiştir.

\footnotetext{
${ }^{1}$ Veri yılları ülkeden ülkeye değişiklik göstermektedir. Enflasyonu yaşama maliyetlerindeki artış oranına göre hesaplamaktadır.
} 
Türkiye'de uzun dönemde paranın dolaşım hızı ve para arzı (M2) enflasyonun temel belirleyicisidir. GSYiH'de yaşanan yüzde 1'lik bir düşüş doğrudan enflasyon oranında yüzde 1'lik bir düşüşe neden olmaktadır. Kirmanoğlu (2001), 1988.05-2000.12 dönemi için Türkiye'yi ele aldığı çalışmasında enflasyonun ekonomik büyümeyi ve yatırımları negatif etkilediğine yönelik sonuçlar elde etmiştir.

Türkiye için yapılan ampirik çalışmalar aşağıda Tablo 1'de özetlenmektedir.

Tablo 1: Türkiye İçin Ampirik Çalışmalar

\begin{tabular}{|c|c|c|c|c|}
\hline Yazar & Uygulama Alanı & $\begin{array}{l}\text { Uygulama } \\
\text { Yöntemi }\end{array}$ & Değişkenler & Bulgular \\
\hline $\begin{array}{l}\text { Karaçor vd. } \\
\text { (2009) }\end{array}$ & $\begin{array}{l}\text { Türkiye/1990 - } \\
2005\end{array}$ & $\begin{array}{c}\text { Eşbütünleşme } \\
\text { ve Nedensellik } \\
\text { Analizi }\end{array}$ & GSYIH ve TEFE & $\begin{array}{l}\text { Enflasyon ekonomik büyüme oranını negatif yönde } \\
\text { etkilemektedir. }\end{array}$ \\
\hline $\begin{array}{l}\text { Karaçor vd. } \\
\text { (2011) }\end{array}$ & $\begin{array}{l}\text { Türkiye/1988:1 } \\
\quad-2007: 4\end{array}$ & Sınır Testi & $\begin{array}{l}\text { Reel GSYIH, TÜFE ve } \\
\text { Reel Gayri Safi Yatırım } \\
\text { Harcamaları/Reel } \\
\text { GSYiH }\end{array}$ & Kısa ve uzun dönemde ilişki negatiftir. \\
\hline $\begin{array}{l}\text { Turhan } \\
(2007)\end{array}$ & $1988: 1-2005: 4$ & $\begin{array}{c}\text { Granger } \\
\text { Nedensellik }\end{array}$ & $\begin{array}{l}\text { TÜFE, GSYIH Deflatörü } \\
\quad \text { ve reel GSYiH }\end{array}$ & $\begin{array}{l}\text { Nedensellik yok ve ilişki negatiftir. Enflasyon } \\
\text { oranlarında yüzde } 10^{\prime} \text { luk bir artış ekonomik } \\
\text { büyümeyi yüzde } 2.5 \text { oranında azaltmaktadır. }\end{array}$ \\
\hline $\begin{array}{c}\text { Berber ve } \\
\text { Artan (2004) }\end{array}$ & $1987: 1-2003: 2$ & $\begin{array}{c}\text { Granger } \\
\text { Nedensellik }\end{array}$ & GSYIH, TÜFE ve TEFE & $\begin{array}{l}\text { Enflasyondan ekonomik büyümeye doğru tek yönlü } \\
\text { bir nedensellik söz konusudur. İlişki negatiftir yani } \\
\text { enflasyon oranındaki yüzde } 10^{\prime} \text { luk bir artış ekonomik } \\
\text { büyümeyi yüzde } 1.9 \text { oranında düşürmektedir. }\end{array}$ \\
\hline Terzi (2004) & $1924-2002$ & $\begin{array}{c}\text { Granger } \\
\text { Nedensellik }\end{array}$ & GSMH ve TÜFE & $\begin{array}{l}\text { Enflasyondan ekonomik büyümeye doğru tek yönlü } \\
\text { ve negatif bir nedensellik söz konusudur. }\end{array}$ \\
\hline Omay (2008) & $1986: 6-2007: 1$ & $\begin{array}{l}\text { VAR-GARCH } \\
\text { yardımıyla } \\
\text { Granger } \\
\text { Nedensellik }\end{array}$ & $\begin{array}{l}\text { TÜFE ve Sanayi Üretim } \\
\text { Endeksi }\end{array}$ & $\begin{array}{l}\text { Enflasyondan ekonomik büyümeye doğru tek yönlü } \\
\text { ve negatif bir nedensellik söz konusudur. Merkez } \\
\text { Bankası'nın fiyat istikrarını korumasına yönelik } \\
\text { politika duruşu optimaldir. }\end{array}$ \\
\hline $\begin{array}{l}\text { Süleymanov } \\
\text { ve Nadirov } \\
\text { (2014) }\end{array}$ & $2003: 1-2013: 4$ & $\begin{array}{c}\text { Granger } \\
\text { Nedensellik }\end{array}$ & GSYIH ve TÜFE & $\begin{array}{l}\text { Büyümeden enflasyona doğru tek yönlü bir ilişki } \\
\text { mevcuttur. Regresyon modeline göre negatif } \\
\text { değerler elde edilmiştir. Ekonomik büyümede } \\
\text { yaşanacak her } 1 \text { puanlık artış, enflasyon oranını } 7.78 \\
\text { puan arttırmaktadır. }\end{array}$ \\
\hline $\begin{array}{l}\text { Esmen vd. } \\
\qquad(2012)\end{array}$ & $1968-2008$ & $\begin{array}{l}\text { ARDL (Sınır } \\
\text { Testi) }\end{array}$ & $\begin{array}{l}\text { GSYiH, Nüfus Büyüme } \\
\text { Oranı, Brüt Sermaye } \\
\text { Brikiminin GSYiH'ya } \\
\text { Oranı, Dış Açıklık ve } \\
\text { TÜFE }\end{array}$ & $\begin{array}{l}\text { İlişki katsayısı negatif } 0.39 \text { olarak düşük bir katsayı } \\
\text { çıktığı için negatif bir ilişki olduğu } \\
\text { söylenememektedir. }\end{array}$ \\
\hline Artan (2008) & $1987: 1-2003: 3$ & GARCH Analizi & $\begin{array}{l}\text { GSYiH, Tüketici Eşya } \\
\text { Fiyatları Endeksi ve } \\
\text { Enflasyon Belirsizliği }\end{array}$ & $\begin{array}{l}\text { Enflasyon belirsizliğinin enflasyona göre ekonomik } \\
\text { büyüme üzerindeki negatif etkisi daha fazladır. } \\
\text { Enflasyon oranındaki yüzde } 1^{\prime} \text { lik bir artış büyümeyi } \\
\text { yüzde } 0.56 \text { oranında azaltırken enflasyon } \\
\text { belirsizliğindeki aynı orandaki bir artış ise ekonomik } \\
\text { büyümeyi yüzde } 3.95 \text { oranında azaltmaktadır. }\end{array}$ \\
\hline $\begin{array}{l}\text { Türkekul } \\
\text { (2007) }\end{array}$ & $1988: 1-2005: 4$ & $\begin{array}{c}\text { Granger } \\
\text { Nedensellik }\end{array}$ & $\begin{array}{l}\text { Tarım Sektörünün } \\
\text { Büyüme Oranı, TÜFE } \\
\text { ve TEFE }\end{array}$ & $\begin{array}{l}\text { Enflasyondan ekonomik büyümeye doğru tek yönlü } \\
\text { ve negatif bir nedensellik söz konusudur. }\end{array}$ \\
\hline $\begin{array}{c}\text { Akyazı ve } \\
\text { Ekinci (2009) }\end{array}$ & 1991:1-2007:12 & $\begin{array}{c}\text { Granger } \\
\text { Nedensellik }\end{array}$ & $\begin{array}{l}\text { Sanayi Üretim Endeksi } \\
\text { ve TÜFE }\end{array}$ & $\begin{array}{l}\text { Enflasyondan ekonomik büyümeye doğru tek yönlü } \\
\text { ve negatif bir nedensellik söz konusudur. }\end{array}$ \\
\hline Karaca (2003) & $1987-2002$ & $\begin{array}{c}\text { Granger } \\
\text { Nedensellik }\end{array}$ & GSYIH ve TÜFE & $\begin{array}{l}\text { Enflasyondan ekonomik büyümeye doğru tek yönlü } \\
\text { ve negatif bir nedensellik söz konusudur. } \\
\text { Enflasyondaki } 1 \text { birimlik artış ekonomik büyüme } \\
\text { oranını } 0.37 \text { birim düşürmektedir. }\end{array}$ \\
\hline $\begin{array}{l}\text { Akgül ve } \\
\text { Özdemir }\end{array}$ & $\begin{array}{l}\text { 2003:01- } \\
2009: 12\end{array}$ & $\begin{array}{l}\text { İki-Rejimli TAR } \\
\text { Modeli }\end{array}$ & Reel GSYiH ve TÜFE & $\begin{array}{l}\text { Enflasyon oranında meydana gelecek bir değişim üç } \\
\text { dönem öncesinden sinyal vermektedir. Enflasyonun } \\
\text { ekonomik büyümeye etkisi enflasyon yüksek } \\
\text { oranlarda ise negatif ve düşük oranlarda ise pozitiftir. }\end{array}$ \\
\hline $\begin{array}{l}\text { Uysal vd. } \\
\text { (2008) }\end{array}$ & $1950-2006$ & $\begin{array}{c}\text { Granger } \\
\text { Nedensellik }\end{array}$ & Enflasyon ve Büyüme & $\begin{array}{l}\text { Enflasyondan ekonomik büyümeye doğru tek yönlü } \\
\text { ve negatif bir nedensellik söz konusudur. }\end{array}$ \\
\hline
\end{tabular}




\section{VERI VE YÖNTEM}

Çalışmada kullanılan veri seti OECD veri tabanından elde edilmiştir. Veriler, 2003:1-2015:4 yılları arasında TÜFE ve reel GSYiH serilerinden oluşmaktadır. Bu kapsamda aşağıdaki Grafik 1'in çalışmada yer alması önem arz etmektedir. Türkiye'de enflasyon ile ekonomik büyüme arasındaki betimsel ilişkinin gösterildiği Grafik 1 incelendiğinde, dönemler itibariyle uluslararası krizin yaşandığı dönem haricinde iki değişken arasında istikrarlı bir ilişkinin olduğu görülmektedir.

Grafik 1: Türkiye'de Enflasyon ve Büyüme (2003:1 - 2015:4)

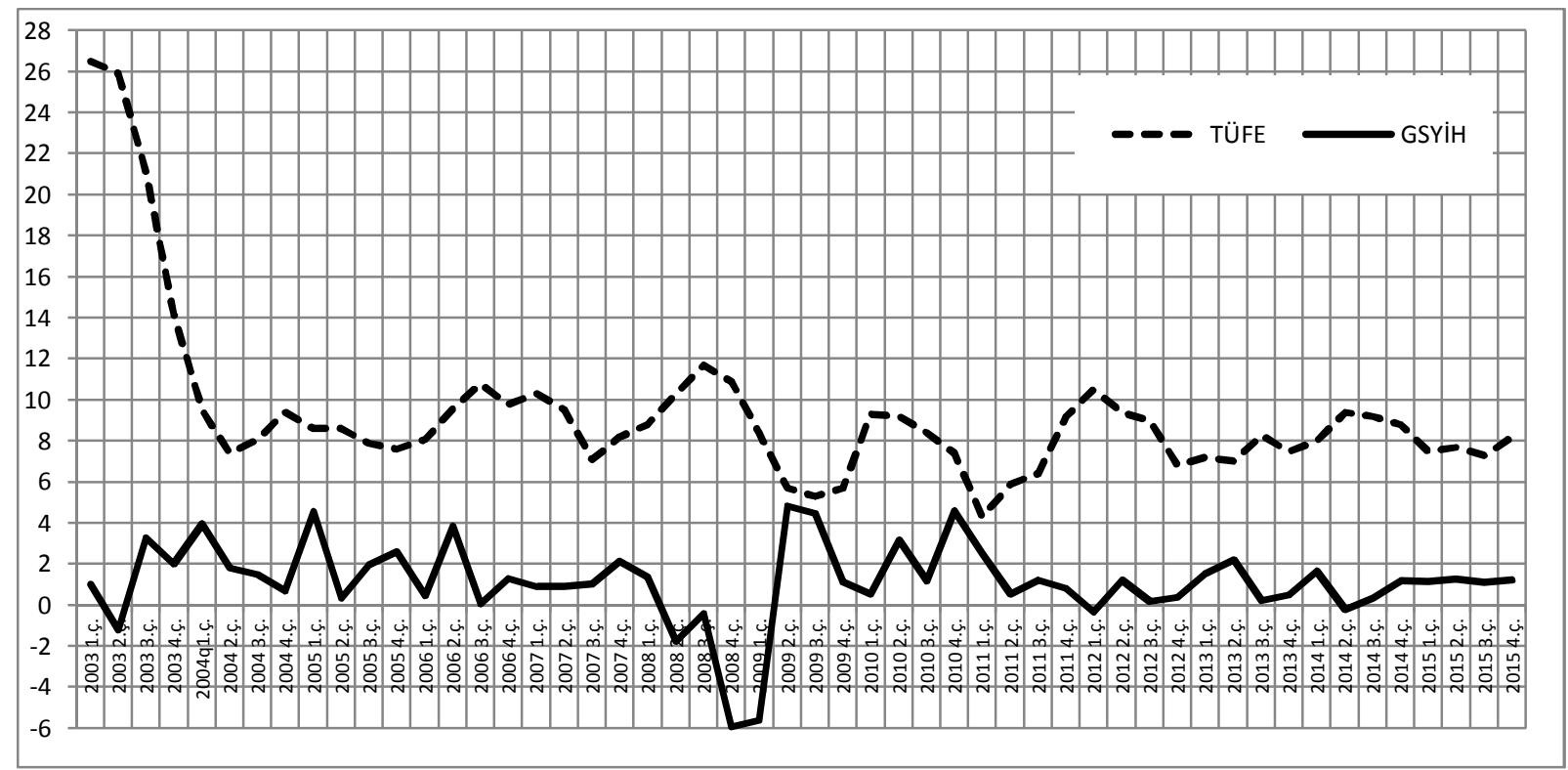

Kaynak: OECD verilerinden tarafımızca hazırlanmıştır.

Enflasyon ve ekonomik büyüme arasındaki ilişkinin araştırılması amacıyla VAR ve Granger Nedensellik testleri yapılmıştır. VAR modeli ilk defa Sim's (1980) tarafından formüle edilmiştir. VAR modeli, yapısal eşanlı denklem modellerine uygulanan teorik kısıtlamalara karşı oluşturulmuştur. VAR modeli, seçilen bütün değişkenleri birlikte ele alır ve bir sistem bütünlüğü içinde inceler. Sıfır kısıtlama uygulanmaz. İçsel-dışsal değişken ayrımına yer verilmez. Tüm değişkenler içsel olarak kabul edilir. Belirli ve modeli yaratan katı bir ekonomik teorinin varlığı kabul edilemez. İktisadi teorinin ileri sürdüğü kısıtlamaların, varsayımlarını model tanımını bozmasına izin vermez. Değişkenler arasındaki ilişkilere hiçbir kısıtlama getirmeden, değişkenlerin zaman içindeki davranışını çeşitli şoklara karşı dinamik tepkiler olarak formüle etmektedir. Tüm modelin hareketleri yapısal şokların değişkenler üzerindeki gecikmeli etkisiyle belirlenir (Yurdakul, 1999: 87-88; Özgen ve Güloğlu, 2004: 95).

İki değişkenli bir VAR modeli şu şekilde ifade edilebilir;

$$
\begin{aligned}
& y_{t}=a_{1}+\sum_{i=1}^{p} b_{1 i} y_{t-i}+\sum_{i=1}^{p} b_{2 i} x_{t-i}+v_{1 t} \\
& x_{t}=c_{1}+\sum_{i=1}^{p} d_{1 i} y_{t-i}+\sum_{i=1}^{p} d_{2 i} x_{t-i}+v_{2 t}
\end{aligned}
$$

Yukarıdaki modelde $P$ gecikmelerin uzunluğunu, $v$ ise ortalaması sıfır, kendi gecikmeli değerleriyle olan kovaryansları sıfır ve varyansları sabit, normal dağılıma sahip, rassal hata terimlerini göstermektedir.

VAR uygulaması için öncelikle iki değişkenin durağanlıklarının birim kök ile test edilmesi, gecikme uzunluklarının belirlenmesi, otokorelasyon, değişen varyans ve istikrar koşulu gibi varsayımların yapılması, etki-tepki fonksiyonları ve varyans ayrıştırmalarının yapılması gerekmektedir.

Çalışmada değişkenlere ait zaman serilerinin durağanlık testi, Genişletilmiş Dickey-Fuller (ADF) ve PhillipsPerron (PP) testleri ile yapılmıştır. ADF ve PP testleri zaman serilerinin durağanlık özelliklerini açıklamak için kullanılmaktadır. Verilerin durağanlığının belirlenmesi istatistiki açıdan doğru sonuçlar elde edilmesini 
sağlamaktadır. Zaman serilerinin durağan olması; zaman ile değişkenler arasındaki ilişkinin bağımsız olması anlamına gelmektedir. ADF testi regresyonu aşağıdaki gibi gösterilmektedir (Gujarati, 2004: 817):

$$
\Delta Y_{t}=\beta_{1}+\beta_{2} t+\delta Y_{t-1}+\sum_{i=1}^{m} \propto{ }_{i} \Delta Y_{t-i}+\varepsilon_{t}
$$

$\Delta$ birinci fark işlemcisi, $t$ zaman trendi, $\varepsilon_{t}$ hata terimi, $Y_{t}$ kullanılan seriler ve $N$ ise bağımlı değişkenin gecikme sayısını ifade etmektedir. PP yaklaşımı ise gecikmeli fark terimleri eklemeden hata terimleri seri korelasyona özen göstererek parametrik olmayan bir düzeltme kullanmaktadır.

Çalışmanın bundan sonraki bölümünde enflasyon ve ekonomik büyüme logaritmik olarak ele alınacaktır ve sırasıyla InCPI ve InGDP şeklinde isimlendirilecektir. Bu değişkenlere ilişkin tanımlayıcı istatistikler Tablo 2'de gösterilmektedir.

Tablo 2: Enflasyon Verilerinin Tanımlayıcı İstatistikleri

\begin{tabular}{lll}
\hline İstatistikler/Değişkenler & InGDP & InCPI \\
\hline Mean & 17.068 & 4.514 \\
Minimum & 16.631 & 3.989 \\
Maximum & 17.368 & 5.014 \\
Standard Deviation & 0.176 & 0.301 \\
Skewness & -0.432 & -0.069 \\
Kurtosis & 2.527 & 1.825 \\
Jarque-Bera & 2.103 & 3.033 \\
\hline
\end{tabular}

\section{BULGULAR VE TARTIŞMA}

Modelde kullanılan iki değişkenin ADF ve PP birim kök testlerine göre durağanlıkları Tablo 3'te yer almaktadır.

Tablo 3: Birim Kök Testi Sonuçları

\begin{tabular}{|c|c|c|c|c|}
\hline \multicolumn{5}{|c|}{ Genişletilmiş Dickey-Fuller Test Sonuçları } \\
\hline & \multicolumn{2}{|c|}{ Düzey } & \multicolumn{2}{|c|}{ Birinci Fark } \\
\hline & Sabitli & Sabit ve Trendli & Sabitli & Sabit ve Trendli \\
\hline $\operatorname{lnCPI}$ & -0.9456 & -2.6469 & $-6.2820 * * *$ & $-6.5092 * * *$ \\
\hline InGDP & -1.5679 & -3.1348 & $-5.7652 * * *$ & $-5.7942 * * *$ \\
\hline \multicolumn{5}{|c|}{ Phillips-Perron Test Sonuçları } \\
\hline & \multicolumn{2}{|c|}{ Düzey } & \multicolumn{2}{|c|}{ Birinci Fark } \\
\hline & Sabitli & Sabit ve Trendli & Sabitli & Sabit ve Trendli \\
\hline $\operatorname{lnCPI}$ & -1.7827 & -2.4711 & $-7.7967 * * *$ & $-8.1060 * * *$ \\
\hline InGDP & -1.5679 & -2.6345 & $-5.7736 * * *$ & $-5.8089 * * *$ \\
\hline
\end{tabular}

Not: Mac Kinnon*,**,*** sırasıyla \%1, \%5ve \%10 kritik değerlerini göstermektedir.

Tablo 3'te ADF ve PP test sonuçları yer almaktadır. Her iki test sonucuna göre de InCPI ve InGDP serileri hem sabitli ve hem de sabitli ve trendli modellerde durağan olmadığı sonucuna ulaşılmıştır. Serilerin birinci farkları alındığında her iki serinin de birinci dereceden durağan oldukları kabul edilmiştir. Bundan sonraki aşamada değişkenler arasında uzun dönem ilişkinin test edilmesi gerekmektedir. Bunun için Engle ve Granger (1987) ve Phillips ve Ouliaris (1990) eşbütünleşme testleri uygulanmıştır. 
Tablo 4: Eşbütünleşme Test Sonuçları

\begin{tabular}{lcccc}
\hline & & & Kritik Değerler \\
\cline { 3 - 4 } Test & Olasılık Değeri & $\% 1$ & $\% 5$ & $\% 10$ \\
\hline E-G Test & -3.426 & -3.9618 & -3.3654 & -3.0657 \\
PO_Zt & -5.935 & -3.9618 & -3.3654 & -3.0657 \\
PA_Za & -42.621 & -28.3218 & -20.4935 & -17.0390 \\
\hline
\end{tabular}

*Testlerin kritik değerleri Phillips-Ouliaris (1990) çalışmasındaki Tablo la ve Tablo Ib'den elde edilmiştir.

Tablo 4'ten görüleceği gibi Engle-Granger testine göre \%5, Phillips-Ouliaris testine göre ise \%1 düzeyinde değişkenler arasında eşbütünleşme olduğu boş hipotezi reddedilmektedir. Dolayısıyla bundan sonra VAR modeli tahmini için öncelikle gecikme uzunluğunun belirlenmesi gerekmektedir.

Tablo 5: VAR Gecikme Uzunluğunun Belirlenmesi

\begin{tabular}{cccc}
\hline Gecikme Uzunluğu & AIC & SC & HQ \\
\hline 0 & -11.5362 & $-11.3787^{*}$ & -11.4769 \\
1 & $-11.6085^{*}$ & -11.2935 & $-11.4900^{*}$ \\
2 & -11.5810 & -11.1086 & -11.4032 \\
3 & -11.5091 & -10.8792 & -11.2721 \\
4 & -11.5327 & -10.7554 & -11.2364 \\
\hline
\end{tabular}

* ilgili kritere göre belirlenen optimal gecikme uzunluğudur.

VAR modelinin gecikme uzunluğunun belirlenmesi için kullanılan en yaygın istatistikler Akaike Bilgi Kriteri (Akeike Information Criterion-AIC), Schwarz Bilgi Kriteri (Schwarz Information Criterion) ve Hannan-Quin Bilgi Kriteri (Hannan-Quin Information Criterion-HQ)'dır. Bu bilgi kriterlerini minimum yapan gecikme uzunluğu optimal olarak kabul edilir. Bu çalışmada VAR modeli için optimal gecikme uzunluğu AIC ve HQ bilgi kriterlerine dayanarak 1 olarak belirlenmiştir.

VAR modelinin geçerliğini sınamak için ilk bakılması gereken kararlılık koşulunun sağlanıp sağlanmadığıdır. Aşağıdaki Şekil 1 incelendiğinde VAR modelinin kökleri daire grafiğinin dışına çıkmadığından kararlılık koşulunun sağlandığı söylenebilir.

\section{Şekil 1: Karakteristik Kökler}

Inverse Roots of AR Characteristic Polynomial

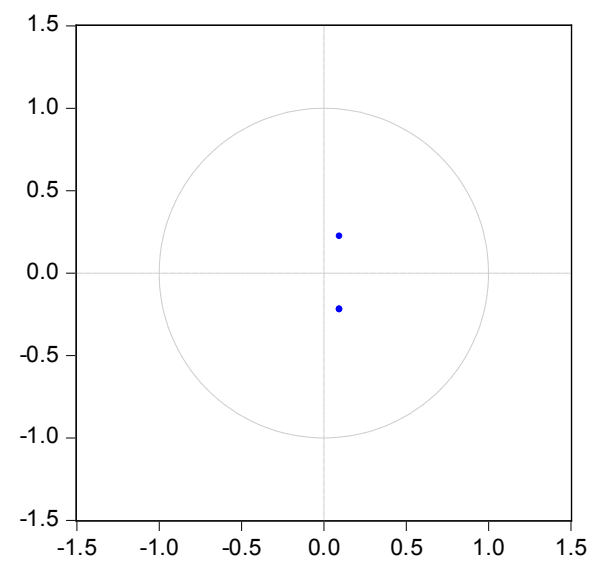

Bundan sonraki aşamada modelde otokorelasyon sorunu olup olmadığı Lagrange Çarpanı (LM) Testi ile sınanmıştır. Tablo 6'ya göre 4. mertebeye kadar yapılan otokorelasyon sınaması sonuçlarının tümünde otokorelasyonun olmadığı boş hipotezi kabul edilmektedir. 
Tablo 6: LM Otokorelasyon Test Sonuçları

\begin{tabular}{ccc}
\hline Gecikme Uzunluğu & LM istatistiği & Olasılık \\
\hline 1 & 4.5553 & 0.3360 \\
2 & 5.7768 & 0.2164 \\
3 & 2.8671 & 0.5803 \\
4 & 5.5851 & 0.2323 \\
\hline
\end{tabular}

Tablo 7'de ise değişen varyans test sonuçları gösterilmektedir. Buna göre White değişen varyans test sonuçlarında değişen varyansın olmadığı boş hipotezi kabul edilmektedir.

Tablo 7: WHITE Değişen Varyans Testi Sonuçları

\begin{tabular}{lll}
\hline Chi-sq & dg & Olasilık \\
\hline 28.0142 & 24 & 0.2594 \\
\hline
\end{tabular}

Tablo 8'de varyans ayrıştırması sonuçları gösterilmektedir. Çalışmada varyans ayrıştırması gerçekleştirilirken, "Cholesky Decomposition" temelli olması nedeniyle E-views programı kullanılmamıştır. Çünkü "Cholesky Decomposition" yöntemi varyans ayrıştırmasında da değişkenlerin sıralamasından etkilenmektedir. Çalışmada yer alan varyans ayrıştırması, değişkenlerin sıralamasından etkilenmeyen "Generalized Impulses" yöntemine göre, tarafımızca hazırlanmıştır.

Tablo 8: Varyans Ayrıştırması

\begin{tabular}{cccc}
\hline $\operatorname{lnGDP}$ & $\underline{\operatorname{lnGDP}}$ & $\operatorname{lnCPI}$ & \multicolumn{1}{l}{$\begin{array}{l}\text { InCPI } \\
\text { InCPI }\end{array}$} \\
\hline 100 & 0 & 0.004967 & 99.99503 \\
99.94869 & 0.051305 & 0.31306 & 99.68694 \\
99.92827 & 0.071727 & 0.441645 & 99.55835 \\
99.91788 & 0.082124 & 0.508415 & 99.49158 \\
99.91157 & 0.088429 & 0.549356 & 99.45064 \\
99.90734 & 0.092657 & 0.577002 & 99.423 \\
99.90431 & 0.095689 & 0.596923 & 99.40308 \\
99.90203 & 0.09797 & 0.611961 & 99.38804 \\
99.90025 & 0.099747 & 0.623715 & 99.37629 \\
99.89883 & 0.101172 & 0.633154 & 99.36685 \\
\hline
\end{tabular}

Tablo 8 incelendiğinde GDP ve CPI'nın nedenlerinin tamamına yakını kendileridir. İlerleyen dönemler ele alındığında yine etkinin aynı şekilde devam ettiği görülmektedir.

Varyans ayrıştırmasından sonra değişkenlerin birbirlerinin nedeni olup olmadığını test etmek amacıyla Granger nedensellik testi uygulanmaktadır. Granger, 1969 yılında nedensellik ve dışsallık kavramlarını ilk defa ileri sürmüştür (Granger, 1969). Eğer $x$ değişkenine ait bilginin modele eklenmesi, ait bilginin modele eklenmesi, $y$ değişkeninin öngörüsüne yardımcı oluyorsa, $x$ değişkeni $y$ 'nin nedenidir. Eğer $\mathrm{H}_{1}$ ve $\mathrm{H}_{2}$ hipotezlerinin her ikisi de reddedilirse, $x$ ve $y$ arasında iki taraflı bir nedensellik olduğu anlaşılmaktadır (Özgen ve Güloğlu, 2004: 96-97).

Tablo 9'da nedensellik testi sonuçları gösterilmektedir.

Tablo 9: Nedensellik Testi Sonuçları

\begin{tabular}{lccc}
\hline & Chi-sq & $\mathrm{df}$ & Olasılık \\
\cline { 2 - 3 } $\begin{array}{l}\text { Bağımsız Değişken: InGDP } \\
\text { InCPI }\end{array}$ & 1.748910 & 1 & 0.1860 \\
\cline { 2 - 3 } $\begin{array}{l}\text { Bağımsız Değişken: InCPI } \\
\text { InGDP }\end{array}$ & 3.655614 & 1 & 0.0559 \\
\hline
\end{tabular}

Tablo 9'a göre olasılık değerleri göz önüne alındığında yüzde 10 anlamlılık seviyesinde enflasyon ile ekonomik büyüme arasındaki nedensellik ilişkisinde ekonomik büyümeden enflasyona doğru tek yönlü nedensellik tespit edilmiştir. Çalışmadan elde edilen bulgulara göre bu çalışma, Süleymanov ve Nadirov (2014) çalışmasının 
sonuçları hariç olmak üzere enflasyondan ekonomik büyümeye doğru bir ilişkinin olduğuna yönelik diğer çalışmalardan ayrılmaktadır.

\section{SONUÇ}

Makroekonomik politika uygulayııılarının en temel hedeflerinden biri düşük enflasyonlu istikrarlı bir ekonomik büyüme hedefidir. Akademik çalışmalarla da desteklenen bu görüşü gerçekleştirmek uzun dönemli bir amaç niteliğindedir. Kısa dönemde özellikle Türkiye gibi yükselen ekonomiler içinde yer alan ülkeler açsından bu dengenin sağlanması yapısal özelliklerinden dolayı kırılgan bir durum sergilemektedir. Bunun yanında uzun dönemli bir hedefe ulaşılması için ise birçok yapısal reformların gerçekleştirilmesi gerekmektedir.

Türkiye ekonomisinde 2003:1-2015:4 dönemi enflasyon ve ekonomik büyüme arasındaki nedensel ilişkinin araştırıldığı çalışmada, ekonomik büyümeden enflasyona doğru istatistiksel yönden anlamlı ve tek yönlü bir ilişkinin olduğu belirlenmiştir. Bu yönüyle Türkiye için yapılmış diğer çalışmalardan farklııklar ortaya koyan çalışmada, özellikle 2001 yılında yaşanan ulusal krizin ardından bir dizi yapısal reform sunan 2002 Acil Eylem Planı́nın ardından uygulanan politikaların ve dünya ekonomisinde yaşanılan daralmaların özellikle de Türkiye'de iç talep destekli ekonomik büyümenin enflasyonu etkilemesi sonuçlarla örtüşmektedir.

Türkiye'nin 2003-2015 yıllarını kapsayan ekonomik durumunu, üçer aylık reel GSYiH ve TÜFE verileriyle betimsel analize dâhil ettiğimiz Grafik 1 incelendiğinde genel olarak istikrara yakın bir görünüm karşımıza çıkmaktadır. Bu yıllara kadar kamu destekli büyüme politikası ve uygulamada gecikme yaşanan anti-konjonktür politikalar, ekonominin uluslararası finansman ihtiyacını arttırmıştır. Büyük ölçüde bütçeden karşılanan kamu yatıımları, bütçe açıklarına neden olmuştur. Döviz kurundaki dalgalanmalar, kamu kesimi borçlanma gereğini hızla arttırmış ve dış borçlanma ön plana çıkmıştır.

Sürdürülemez olan dış borçlar ve ekonomik istikrarsızlıklar, siyasi istikrarsızlıklarla desteklenmiş ve 1998'de yaşanan uluslararası kriz, 1999 İstanbul depremi Türkiye ekonomisinin bir kez daha krize girmesine neden olmuştur. Tekrar uygulamaya konulan istikrar politikaları ile durum 2001 yılına kadar sürdürülebilmiştir. Uygulanan yanlış ve gecikmeli maliye politikaları; bağımsız para politikası ve sermaye hareketi karşısında uygulanan bant içinde dalgalı kur rejiminden vazgeçilmek zorunda kalınması 2001 krizini tetiklemiştir. 2001 sonrası dış borçlanma yerine iç borçlanmaya önem verilmiş, özel sektörün ve hanehalkının borçlarında artış meydana gelmiştir. Bütçe açığı düşmüş, cari açık artmıştır. Tasarrufların azalması, efektif talepte meydana gelen azalışlar enflasyonun düşmesini sağlamıştır.

Çalışmada analize konu olan 2003 yılında başlayan istikrar politikası ile bir önceki istikrar politikası desteklenmiş ve uygulanması mali disiplin temel alınarak güçlendirilmiştir. Temel olarak enflasyon çıpa olarak gösterilmiş, amaç ise en kısa sürede tek haneli rakamları yakalamak olarak belirtilmiştir. Büyüme ise düşük faizli krediler ile iç talep destekli ve ihracata dayalı olarak gerçekleştirilmeye çalışılmıştır. Uluslararası krediler ile desteklenen düzenlemeler, bankacılık sektörü düzenlemeleri ve kamu yönetiminde yeni yasaların uygulanmasıyla, kamu tasarrufları ve vergi gelirleri arttırılmaya çalışılmışır. Bu durum bütçesel yükü azaltmış, toplam kamu borcunda düşüş sağlamıştır.

Özel sektöre sağlanan teşvik ve ucuz kredi imkanları, özel sektörün ve hanehalkının tüketimlerini arttırmış, tasarruf oranlarında düşüşe neden olmuştur. Büyümenin temelini teşkil edecek olan özel sektörün yatırımlarındaki ve üretimindeki artış, büyüme üzerinde etkili olamamıştır. Yurtiçi ve yurtdışında yaşanan olumsuzlukların etkisi, döviz kuru ve dolayısıyla ihracata dayalı büyüme üzerinde olumsuzluklara neden olmuş, ihracat içindeki ithal malların maliyetlerinde artışa neden olmuştur. Bütçe disiplini sağlanmış ancak özel sektörün ve hanehalkının borçlanmalarında artı̧ meydana gelmiştir. Üretim ile desteklenemeyen bireysel harcamalar, iç talep olarak büyümeyi belli bir seviyede tutmuş ancak enflasyonun istenilen seviyeye inmesini de engellemişstir.

2008 yılında yaşanan uluslararası finansal krizin olumsuz etkisi, ihracata dayalı büyüme stratejisi izleyen Türkiye ekonomisini bir sonraki yıl ortadan kalkmış, iç talebin desteğiyle büyüme oranında artış sağlanmış, arz fazlalığı sebebiyle ise enflasyon oranında düşüş oluşmuştur.

Enflasyonun tek haneli rakamlara düşmesi, büyüme oranında yaklaşık yüzde $4^{\prime}$ lük bir oranın yakalanması ekonomik istikrar olarak görülmektedir. Ancak kurlardaki değişme, dış talep yetersizliği sebebiyle gerekli üretim 
artışının oluşmaması, kişi başına düşen geliri dolar bazında arttırmamakta ve enflasyonun istenilen seviyede tutulmasını engellemektedir.

\section{KAYNAKÇA}

Ahmed, S. ve Mortaza, Md.G. 2005, "Inflation and Economic Growth in Bangladesh: 1981 -2005”, Policy Analysis Unit Working Paper Series, WP0604, pp. 1-22.

Akgül, I. ve Özdemir, S. 2012, “Enflasyon Eşiği ve Ekonomik Büyümeye Etkisi”, iktisat, İşletme ve Finans, Vol. 27, No. 313, ss. 85-106.

Akyazı, H. ve Ekinci, A. 2009, “Enflasyon Hedeflemesi, Büyüme ve Türkiye Cumhuriyet Merkez Bankası”, Bankacılar Dergisi, Sayı: 68, ss. 319.

Artan, S. 2008, "Türkiye'de Enflasyon, Enflasyon Belirsizliği ve Büyüme", International Journal of Economic and Administrative Studies, Vol. 1 , No. 1 , ss. $113-138$.

Barro, R.J. ve Sala-i-Martin, X. 1992, "Public Finance in Models of Economic Growth”, The Review of Economic Studies, Vol. 59, Issue 4, Oct., pp. 645-661.

Barro, R.J. 1995, “Inflation and Economic Growth”, NBER Working Paper 5326.

Baumol, W. J. 1958, "Price Behavior, Stability, and Growth", The Relationship of Prices to Economic Stability and Growth, Joint Committee Print.

Berber, M. ve Artan, S. 2004, "Enflasyon ve Ekonomik Büyüme İlişkisi: Türkiye Örneği”, Turkish Economic Association Discussion Paper $2004 / 21$.

Borrero, A. M. 2001, "On the Long and Short of Central Bank Indepence, Policy Coordination, and Economic Performance", IMF Working Paper, WP/01/19, pp. 1-25.

Bozkurt, C. 2014, “Money, Inflation and Growth Relationship: The Turkish Case", International Journal of Economics and Financial Issues, Vol. 4, No. 2, pp. 309-322.

Bruno, M. ve Easterly, W. 1998, "Inflation Crises and Long-Run Growth”, Journal of Monetary Economics, Vol. 41, pp. 3-26.

Dıckey, D.A. ve Fuller, W.A. 1979, "Distribution of the Estimators for Autoregressive Time Series with a Unit Root", Journal of The American Statiscal Association, No. 74, pp. 427-431.

Domar, E. D. 1946, “Capital Expansion, Rate of Growth, and Employment”, Econometrica, Vol. 14, No. 2, pp. $137-147$.

Harrod, R.F. 1939, “An Essay in Dynamic Theory”, The Economic Journal, Vol. 49, No. 193, pp. 14-33.

Engle, R. F., and Granger, C. W. J. 1987, "Co-Integration and Error Correction: Representation,Estimation and Testing," Econometrica, 55, 251-276.

Esmen, Ö.S., Turan, S.A. ve Aksu, H. 2012, "Sınır Testi ile Enflasyon ve Ekonomik Büyüme İlişkileri: Türkiye Üzerine İncelemeler", Anadolu Üniversitesi Sosyal Bilimler Dergisi, Cilt: 12, Sayı: 2, ss. 25-40.

Faria, J. R. ve Carneiro, F. G. 2001, “Does High Inflation Affect Growth in the Long and Short Run”, Journal of Applied Economics, Vol. 4, No. 1, pp. 89-105.

Fischer, S. 1993, "The Role of Macroeconomic Factors in Growth", NBER Working Paper Series, Working Paper No. 4565, pp.1 36.

Granger, C. W.J. 1969, "Investigating Causal Relations by Econometric Models and Cross-Spectral Methods", Econometrica, No. 37, No. 3, pp. 553-56-.

Ghosh, A. ve Phillips, S. 1998, “Warning: Inflation May Be Harmful to Your Growth”, IMF Staff Papers, Vol. 45, No. 4, pp. 672-710.

Gillman, M., Harris, M. ve Matyas, L. 2002, "Inflation and Growth: Some Theory and Evidence", Berlin: 10th International Conference on Panel Data, http://econpapers.repec.org/cpd/2002/42_Harris_2.pdf.

Gillman, M. ve Harris M., 2010, “The Effect of Inflation on Growth, Economics of Transition”, Vol. 18, No. 4, pp. 697-714.

Gokal, V. ve Hanif S. 2004, "Relationship Between Inflation and Economic Growth", Economics Depertmant Reserve Bank of Fiji Working Paper, 2004/4, pp. 1-51.

Gujarati, D. N. 2004, Basic Econometrics, Fourth Edition, The McGraw-Hill Companies, USA.

Jayathileke, P.M.B. ve Rathnayake, R.M.K.T. 2013, "Testing the Link between Inflation and Economic Growth: Evidence from Asia”, Modern Economy, Vol. 4, pp. 87-92.

Kaldor, N. 1957, “A Model of Economic Growth”, The Economic Journal, Vol. 67, No. 268, pp. 591-624. 
Karaca, O. 2003, “Türkiye'deki Enflasyon - Büyüme İlişkisi: Zaman Serisi Analizi”, Doğuş Üniversitesi Dergisi, Cilt:4, No. 2, ss. $247-255$.

Karaçor, Z., Şaylan, Ş. ve Üçler, G. 2009, "Türkiye Ekonomisinde Enflasyon ve Ekonomik Büyüme İlişkisi Üzerine Eşbütünleşme ve Nedensellik Analizi (1990 - 2005)", Niğde Üniversitesi IïF Dergisi, Cilt: 2, Sayı: 2, ss. 60-74.

Karaçor, Z., Özer, H. Ve Saraç, T.B. 2011, “Enflasyon ve Ekonomik Büyüme illişkisi: Türkiye Ekonomisi Üzerine Ekonometrik Bir Uygulama (1988-2007)", Niğde Üniversitesi IiBF Dergisi, Cilt: 4, Sayı: 2, ss. 29-44.

Khan, M.S. ve Senhadji, A.S. 2001, “Threshold Effects in the Relationship Between Inflation and Growth", IMF Staff Papers, Vol. 48, No. 1, pp. 1-21.

Kirmanoğlu, H. 2001, "Is There Inflation-Growth Tradeoff in the Turkish Economy?", CEA 35th. Annual Meeting McGill University, Montreal, May31-June3, pp.1-13.

Lucas, R.E. 1988, “On The Mechanics of Economic Development”, Journal of Monetary Economics, 22 (1), pp. 3-42.

Mallik, G. ve Chowdhury, A. 2001, "Inflation and Economic Growth: Evidence From Four Asian Countries", Asia-Pacific Development Journal, vol. 8, No. 1, pp. 123-135.

Mubarik, Y. A. 2005, “Inflation and Growth: An Estimate of the Threshold Level of Inflation in Pakistan", SBP-Research Bulletin, Vol. 1, No. 1, pp. 35-44.

Mundell, R.A. 1965, “Growth, Stability, and Inflationary Finance”, Journal of Political Economy, Vol. 73, No. 2, pp. $97-109$.

Omay, T. 2008, "Enflasyon ve Büyüme Belirsizliklerinin Enflasyon ve Büyüme İle Olan İlişkileri: Türkiye Örneği”, Çankaya Üniversitesi FenEdebiyat Fakültesi Journal of Arts and Sciences, Sayı: 10, ss. 81-108.

Özgen, F.B. ve Güloğlu, B. 2004, "Türkiye'de İç Borçların İktisadi Etkilerinin VAR Tekniğiyle Analizi”, METU Studies in Development, Sayı: 31, ss. 93-115.

Phillips, P. C. B. , and Ouliaris, S. 1990, Asymptotic Properties of Residual Based Tests for Cointegration, Econometrica, Vol. 58, No. 1 (Jan., 1990), pp. 165-193

Romer, P.M. 1986, “Increasing Returns and Long-Run Growth”, The Journal of Political Economy, Vol. 94, No. 5, Oct, pp. $1002-1037$.

Samuelson, P.A. Ve Solow, R.M. 1960, “Analytical Aspects of Anti-Inflation Policy”, The American Economic Review, Vol. 50, No. 2, pp. 177194.

Sarel, M. 1996, “Nonlinear Effects of Inflation on Economic Growth”, IMF Staff Papers, Vol. 43, No. 1.

Sidrauski, M. 1967a, "Rational Choice and Patterns of Growth in a Monetary Economy", The American Economic Review, Vol. 57, Issue 2, pp. 534-544.

Sidrauski, M. 1967b, “Inflation and Economic Growth”, The Journal of Political Economy, Vol. 75, No. 6, pp. 796-810.

Sims, C. A. 1972, “Money, Income, and Causality”, American Economic Review, Vol. 62, pp. 540-552.

Solow, R.B. 1956, "A Contribution to the Theory of Economic Growth”, The Quarterly Journal of Economics, Vol. 70, No. 1, Feb., pp. 65-94.

Süleymanov, E. ve Nadirov, O. 2014, "Türkiye Örneğinde Enflasyonla Ekonomik Büyüme Arasında Ilişki", Journal of Qafqaz University Economics and administration, Vol. 2, No. 2, pp. 119-125.

Terzi, H. 2004, “Türkiye’de Enflasyon ve Ekonomik Büyüme illişkisi (1924-2002)”, Gazi Üniversitesi iiBF Dergisi, Cilt: 6, Sayı:3, ss. 59-75.

Tobin, J. 1965, "Money and Economic Growth", Econometrica, Vol. 33, Issue 4, pp. 671-684.

Tun Wai, U. 1959, "The Relation between Inflation and Economic Development: A Statistical Inductive Study", IMF Staff Papers, Vol. 7, No. 2, pp. 302-317.

Turhan, S.E. 2007, “Enflasyon ve Ekonomik Büyüme iliş̧kisi: Türkiye Örneği”, Kahramanmaraş Sütçü İmam Üniversitesi Sosyal Bilimler Enstitüsü Yayımlanmamış Yüksek Lisans Tezi, Dnş: Sami Taban.

Türkekul, B. 2007, “Türkiye'de Enflasyon-Büyüme İlişkisi: Tarım Sektörü İtibariyle Ekonometrik Analiz”, Ege Üniversitesi Ziraat Fakültesi Dergisi, Cilt: 44, Sayı: 1, ss. 163-175.

Uysal, D., Mucuk, M. ve Alptekin, V. 2008, "Türkiye Ekonomisinde Vektör Otoregresif Model ile Enflasyon - Büyüme İlişkisinin Analizi”, ZKÜ Sosyal Bilimler Dergisi, Cilt: 4, Sayı:8, ss. 57-71.

Yurdakul, F.A. 1999, “Hendry ve Sims Yöntemlerinin Teorik Olarak Karşılaştırılması”, Gazi Üniversitesi Ekonomik Yaklaşım Dergisi, Cilt: 10, Sayı: 33, pp. 84-91. 